\title{
Views of Prospective Science Teachers on Including the Concept of Plasma in Science Curricula
}

\author{
Mustafa Zafer Balba $\breve{g}$ \\ Assoc. Prof., Eskisehir Osmangazi University, Turkey, zbalbag@ogu.edu.tr
}

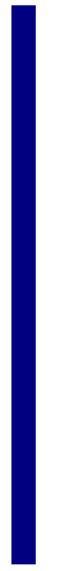

\begin{abstract}
States of matter are structures that we may easily encounter in the universe as well as our close environment. The plasma state is the fourth state of matter, and it has much different properties in comparison to the solid, liquid and gas states of matter. In order to understand the universe and the environment we live in better, one needs to have knowledge on the fundamentals of the concept of plasma. Therefore, it is believed that the fourth state of matter, plasma, should be included in science curricula based on the cognitive development levels of students. Based on this idea, this study investigated the views of prospective science teachers who took the course "plasma physics and technologies" which is an elective course in the undergraduate science teaching program at the faculty of education at a state university in Turkey on the class levels and methods to teach students the concept of plasma. Accordingly, the aim of the study is to determine the views of prospective science teachers about plasma concept and teaching. The prospective science teachers stated that the concept of plasma should be included in science curricula on the levels of primary school and middle school.
\end{abstract}

Keywords: plasma, prospective teachers, states of matter, curriculum, science

\section{INTRODUCTION}

Considering the history of science, the question what the first matter that created the universe was has concerned humankind since the ancient ages. This concept, which forms the basis of the Ionian School of philosophy (between the $5^{\text {th }}$ and $7^{\text {th }}$ centuries BC) and is named substance (substantia), is water according to Thales, infinity according to Anaximandros, air according to Anaximenes, seed according to Anaxagoras, number according to Pythagoras, atom according to Democritus, and fire according to Heraclitus (Topdemir \& Unat, 2009; Kranz, 1994). Within this context, it is still a wonder what the first matter that created the universe was, and it is seen that the answer to this question is being sought today in studies conducted by the European Organization for Nuclear Research (CERN). The most valid theory today regarding the formation of the universe is the Big Bang Theory. This theory depends on the idea that the universe emerged out of an extremely dense and hot point billions of years ago. Based on this theory, some

Citation: Balbağ, M. Z. (2018). Views of Prospective Science Teachers on Including the Concept of Plasma in Science Curricula. International Journal of Instruction, 11(2), 569-584. https://doi.org/10.12973/iji.2018.11239a 
scientists argue that the first state of matter may have been fire, therefore, plasma. Today, on the other hand, plasma is accepted as the fourth state of matter, following the solid, liquid and gas states. Considering the quantities found in the universe, the plasma state is much more abundant than the other states. It is stated that $99 \%$ of the universe is in the state of plasma.

Plasma is a state which we can easily encounter in the universe and in our close environment. If enough energy is provided to matter in its gas state, the fourth state of plasma may be created. Development of stable-state Direct Current (DC) arc discharge in 1808 by Sir Humphry Davy and development of the high voltage DC electrical discharge tube in 1830 by Michael Faraday and his colleagues were the first studies that led to the discovery of the fourth state of matter. Electrical discharge in gases was later studied by Sir William Crookes, and in 1879, Crookes stated that an ionized gas is the "fourth state of matter". For the first time in 1929, Irving Langmuir named an ionized collection of gas as "plasma" (Tonks \& Langmuir, 1929). Thus, plasma is also stated to be ionized gas. Today, on the other hand, in addition to ionized gas atoms, it is known that the plasma state is also a high-energy state that contains electrons, photons, neutral atoms, negative ions, positive ions, radicals, and stimulated atoms and molecules (Tanenbaum, 1967). From our close surroundings to further away, examples of the fourth state of matter may be listed as fire, lightning, thunder, auroras, the ionosphere, the magma layer, neon advertising lights and xenon lights of cars, fluorescent lights at our homes, the sun, the stars, interstellar space, Van Allen belts, solar winds and supernovas. There are also plasma sources that are used in laboratory studies which produce plasma (Grill, 1993).

Plasma is described as a collection of positively and negatively charged particles that are electrically neutral together and move in random direction. That is, plasma consists of a collection of free-moving electrons and ions, and atoms that lost their electrons. While plasma is confused with gases very frequently, it is a structure that has various properties. An important characteristic of plasma is that it behaves as a neural structure although it consists of charged particles. Although it is electrically neutral, it interacts with electrical and magnetic fields. Additionally, plasma is conductive, and the particles inside it move collectively (Grill, 1993).

In the light of all these, it is highly important that the concept of plasma, which has various characteristics, is used in science education. This is because today, the concept of plasma and technologies related to it are already in our lives. Regarding the history of plasma, it is seen that studies that started in the 1800s in the world are still very new for Turkey. Especially considering that various objects and events we observe around us are related to the concept of plasma, it should be inevitable that the basics of this concept are used in science curricula within the Turkish education system. It is seen that the concept of plasma is introduced on the level of 9th grade in high school in the Turkish education system. It was observed that the concept of plasma was not included at all up to the 9th grade in high school, but some teachers who have a bit of knowledge on it verbally mentioned it as the fourth state of matter. In summary, students are not taught the concept of plasma up to the 9th grade in high school. However, the concept of 
plasma is so close to us. The sun we see when we wake up, the stars we observe at nights, lightnings and thunders that get our attention on rainy days, flames that come out when we turn on the stove, fluorescent and neon lights we use at our homes, xenon lamps in our cars, the candle, lighter and match flames that we need occasionally, plasma televisions we use at home, all these are based on the concept of plasma. Children observe these starting at very early ages, but they are not able to get an idea on the basic structure or these and how they can work. They do not even have any idea about the concept. This situation shows the need for and importance of teaching the concept of plasma.

Concept teaching is one of the main subjects of science education in primary education (corresponding to primary schools and middle schools in Turkey). Effective science education facilitates students' development of research skills related to concepts and conceptual systems that constitute the foundations of their creativity and scientific thinking (Başar, 1992). Learning the basic concepts of science correctly in the primary education process is highly important for learnings that will take place in future years (Çiçek, 2008). This is because misunderstandings and misconceptions of students affect future learnings of them and create a resistance against change (Hewson \& Hewson, 1983; Nakhleh, 1992; Pardo \& Partoles, 1995; Zoller, 1990). One of the factors that affect learning is, as strongly focused on by Ausubel (1963), the preliminary knowledge of the student. If students are able to relate new information to their existing knowledge while learning a new thing, they can achieve meaningful learning and apply this to different problem situations. Therefore, teaching them the basics of the concept of plasma by considering their cognitive development will lead them to not only make sense of their close surroundings but also meaningfully learn about various subjects based on the concept of plasma in the future. The results of this study agreed with this idea, because almost all of the prospective science teachers who participated in the study stated that the concept of plasma should be included on the levels of primary school and middle school. This outcome is also important in terms of the vision of science curricula. The objective of science curricula is to train all students as scientifically literate individuals. According to the Turkish Ministry of National Education (MEB), scientifically literate individuals are individuals who investigate, inquire, make effective decisions, solve problems, are self-confident and open for collaboration, communicate effectively, and learn throughout their lives with awareness on sustainable development (MEB, 2017). Individuals' investigation, inquiry and creation of necessary ways of solution may only be possible by their awareness of scientific problems with an innovative approach. This foundation is also a requirement for them to become useful for their country. This will be possible by developing modern education programs and bringing them up to a level that will meet the expectations of the times (Varış, 1996). In this sense, the purpose of this study was to investigate the views of prospective science teachers on at what point and how the concept of plasma, should be included in science curricula considering the cognitive development of students.

How the concept of plasma should be included in the primary school and middle school science curricula and which goals and limitations it should have, are issues that need to be discussed. Based on the expertise and experience of the researcher in the field of 
plasma, the results of this study suggest that it would be suitable to introduce the concept of plasma much earlier than the 9th grade in high school, preferably on the levels of primary school and middle school. The exact levels on which and the ways how the concept will be introduced may be determined by studies conducted by expert teams who organize the curricula in the education system. With this study, it was aimed to propose ideas to committees working on curricula. While presenting such studies, it should not be sufficient to only determine a current issue and express its necessity. It is definitely a must to conduct detailed studies regarding how to include current science subjects that are thought to be necessary in curricula. In order for subjects that are considered for inclusion in primary school and middle school science curricula to be integrated, firstly, their necessity for the education-training system should be emphasized, problems of understanding other disciplines created by exclusion of the subject should be determined, and attention should be paid to the relationship of such subjects with the environment and being able to explain frequent events in the environment, as well as achieving integration with the world while doing all these (Bülbül, 2009).

Moreover, if the subject will be included in curricula, the ways to include it should be investigated from different perspective. For example: How much necessity is there? What kind of goals should one determine? On what class level should it be introduced? Under which subject titles should it be provided? Which outcomes should be aimed? Through which methods and techniques should it be provided? It should be noted that, the thinking process in this study might not have been as detailed as that of a curriculum design expert. However, it is expected that the views of last-year prospective science teachers will provide a contribution in the context of the research questions. The reasons that this study was conducted with prospective science teachers were that they had taken an elective course about the basics of plasma physics, that is, they had sufficient field knowledge regarding the basics of the subject, they were easily accessible and consulted. There are difficulties in reaching officially employed teachers who are appointed by the state, and issues regarding intense paperwork and formalities.

Additionally, in the light of the experiences of the researcher, it was seen that the knowledge of science teachers on the concept of plasma is very limited. It is known and declared on various platforms that teachers in Turkey should improve themselves. In this sense, it becomes a significant outcome that teachers, who are at the center of transformation, adapt to changes in the world and increase their professional development towards their field in a positive way (Bilgin \& Balbağ, 2016). In case the results presented by this study affect curricula, it will be possible to open in-service training courses where teachers will get themselves up to date.

\section{Purpose of the Study}

The purpose of this study is to reveal the views of prospective science teachers on the concept of plasma and teaching. Therefore, this study is of high importance. For this purpose, the prospective science teachers were asked to answer the following questions:

1) What are the views of science teacher candidates regarding the concept of plasma to be included in science curricula? 
2) What are the views of science teacher candidates regarding the realization of plasma concept teaching?

3) What are the views of prospective science teachers on evaluating plasma concept teaching?

\section{METHOD}

\section{METHOD}

\section{Research Design}

The study used a phenomenology design as a qualitative research method. Phenomenology studies aim to reveal and interpret individual perceptions regarding a phenomenon (Yıldırım \& Şimşek, 2008). The fact that this study is deeply examined is the experiences of teacher candidates towards plasma. In other words, it is defined as perceptions about a concept or a fact in the lives of individuals (Creswell, 1998). It is stated that the phenomena can be confronted in various forms, such as events, experiences, perceptions, orientations, concepts and situations in the world we live in. (Yıldırım \& Şimşek, 2008).

\section{Participants}

The participants of the study consisted of a total of 35 prospective science teachers who were in their 4th year at a Faculty of Education of a state university in Turkey in the academic year of 2016-2017. The participants were selected by the method of criterion sampling. As the participants had taken the elective course on Plasma Physics and Technologies and attended teaching internships regarding their fields in school environments, the selection criterion was determined as having observed the contents and applications in science curricula. The main reason for determining this criterion was the aim for prospective teachers who had field knowledge regarding the subject of basics of plasma and opinions about existing practices and programs. Characteristics of the participants are given in Table 1.

Table 1

Characteristics of the Participants

\begin{tabular}{lllc}
$\begin{array}{l}\text { Prospective } \\
\text { Teacher }\end{array}$ & Sex & Class Level & $\begin{array}{c}\text { Success Level in the Plasma Physics and } \\
\text { Technologies Course (over 100 points) }\end{array}$ \\
\hline T1 & Male & 4th Year & 84 \\
\hline T2 & Female & 4th Year & 81 \\
\hline T3 & Female & 4th Year & 90 \\
\hline T4 & Female & 4th Year & 92 \\
\hline T5 & Female & 4th Year & 73 \\
\hline T6 & Female & 4th Year & 95 \\
\hline T7 & Female & 4th Year & 76 \\
\hline T8 & Female & 4th Year & 63 \\
\hline T9 & Female & 4th Year & 84 \\
\hline T10 & Female & 4th Year & 78 \\
\hline T11 & Female & 4th Year & 66 \\
\hline T12 & Female & 4th Year & 72 \\
\hline T13 & Female & 4th Year & 61 \\
\hline
\end{tabular}




\begin{tabular}{llll}
\hline T14 & Female & 4th Year & 81 \\
\hline T15 & Male & 4th Year & 73 \\
\hline T16 & Female & 4th Year & 76 \\
\hline T17 & Male & 4th Year & 76 \\
\hline T18 & Female & 4th Year & 61 \\
\hline T19 & Female & 4th Year & 68 \\
\hline T20 & Female & 4th Year & 82 \\
\hline T21 & Male & 4th Year & 59 \\
\hline T22 & Female & 4th Year & 65 \\
\hline T23 & Female & 4th Year & 96 \\
\hline T24 & Female & 4th Year & 89 \\
\hline T25 & Female & 4th Year & 64 \\
\hline T26 & Female & 4th Year & 66 \\
\hline T27 & Female & 4th Year & 71 \\
\hline T28 & Female & 4th Year & 74 \\
\hline T29 & Female & 4th Year & 93 \\
\hline T30 & Female & 4th Year & 79 \\
\hline T31 & Female & 4th Year & 89 \\
\hline T32 & Female & 4th Year & 85 \\
\hline T33 & Male & 4th Year & 95 \\
\hline T34 & Female & 4th Year & 84 \\
\hline T35 & Female & 4th Year & 87 \\
\hline & & &
\end{tabular}

As seen in Table 1, 5 of the participants were male, while the other 30 were female. All 35 participants were 4th-year students; they had taken part in teaching internships and taken the elective course on plasma physics and technologies by the spring semester of the academic year of 2016-2017. It may be seen that they had high success levels in the course.

\section{Data Collection}

The data were collected by an open-ended questionnaire form developed by the researcher as a semi-structured interview tool. Rubin (1983) classified interviews in four types as fixed format interviews, open-ended interviews, open-ended sensitizer interviews and open-ended in-depth interviews. The second type of interviews, "open ended interviews," resembles structured interviews in terms of method and content. In open-ended interviews, there is a set of standard questions and the interviewee is free to answer these questions in a way they like and subjectively (Yıldırım \& Şimşek, 2008). The open-ended questionnaire used in the study consisted of two parts. The first part comprised questions on the participants' sex, whether they took the teaching internship course or not, whether they took the plasma physics and technologies elective course or not, and their success levels. The second part included questions for determining their views on inclusion of the concept of plasma in science curricula.

\section{Data Analysis}

The data of the study were analyzed using the techniques of descriptive analysis. The purpose of descriptive analysis is to present the obtained findings to the reader in an organized and interpreted way (Yıldırım \& Şimşek, 2008). Firstly, the data that are obtained with this purpose are described in a logical and comprehensible way. Then, 
these descriptions are interpreted, causality relationships are examined, and a set of results is reached. Within this context, firstly the open-ended questionnaire responses were checked, and empty forms were removed. The questionnaire forms were then numbered. While analyzing the data of the study, the themes were formed based on the questions. In this context, the data obtained for each question were analyzed, and raw codes were derived. Categories were created by relating the obtained codes amongst each other. The researcher carried out the process of deriving the codes and forming the categories by receiving help from other researchers who are experts on this topic in a discussion setting. Necessary adjustments and relations were carried out together, and the themes took their final form.

In the research, qualitative data collection tools have been used for credibility, transferability, consistency and verifiability criteria for collected data. In this study, expert opinion and participant questionnaires were applied in the development of data collection tools and analysis of data to ensure credibility. In order to ensure the consistency and verifiability of the study, it was presented to experts in all processes from the preparation of data collection tools to the analysis. As a result of the discussions with the experts, the themes and codes have been given final forms. In addition, the researchers worked simultaneously with other researchers at all stages from the preparation of the data collection tools to the interpretation and reporting of the findings, and the data were analyzed separately and feedback and corrections were made.

\section{FINDINGS}

According to the findings obtained in the study, inclusion of the concept of plasma in science curricula had dimensions of "class level", "outcomes", "content", "learningteaching process" and "measurement-assessment process".

\section{Findings on Class Level}

The views of the participants on the class levels of including the concept of plasma in science curricula are given in Figure 1.

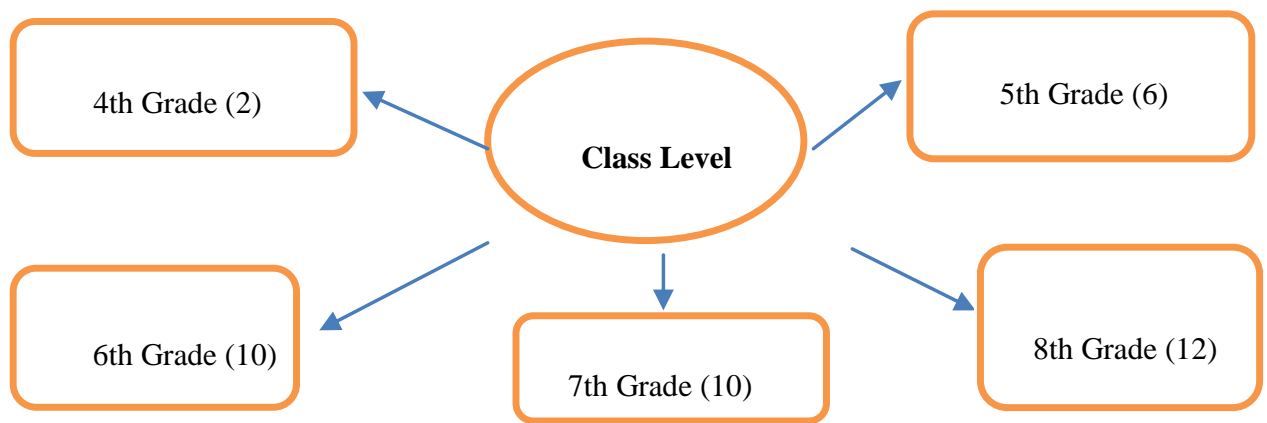

Figure 1

Views of the prospective teachers on the class levels on which they thought the concept of plasma should be included in science curricula 
As seen in Figure 1, the participants provided different views on the class levels on which the concept of plasma should be included in science curricula. Most of the participants stated that the concept of plasma should be included in 6th, 7th and 8thgrade science curricula. T3, who thought that it should be included in 5th, 6th and 8thgrade curricula explained their opinions as 'the concept of plasma should definitely be mentioned while discussing the subject of states of matter. Examples should be provided. This should happen around 5th and 6th grades. Here, students should be encouraged to develop a sense of curiosity and challenge their imagination' and added, 'it would be appropriate to teach the subject of plasma in the 8th grade in more detail. I think, this way, talking about the structure of plasma would appeal to their levels of comprehension and perception.' The views of T3 may be interpreted as that they thought a sense of plasma should be provided to students in the 5th and 6th grades, while the subject should be taught in more detail in further grades. T10 explained their view that the subject should be included in 8th grade curricula as "plasma is an abstract concept and even families do not have an idea about it. This is why the 6th and 7th grades are not suitable for it. The subject would be more lasting and easily comprehensible if it is included in the 8th grade.'

According to T10, plasma is an abstract concept and it should be included in curricula when students transition to their developmental period of abstract operation. T14 provided their views as 'it should be taught on the class level where the concepts of astronomy and universe are introduced. It should be taught in the 5th, 6th, 7th and 8th grades under different subject titles in each grade by increasing the level in grades that include units related to astronomy and getting deeper into the subject.' T14's views may be interpreted as they thought the subject should be taught in every grade from the 5th grade to the 8th grade in a spiral schedule where the concepts of astronomy and universe are provided. T17 stated that the subject of plasma should be taught in the 5th grade and said, 'the most important contribution of introducing students to plasma in the 5th grade would be that it provides familiarity.' T23 stated that 'it should be taught in the 8th grade, because states of matter, changes of state and different behaviours of particles of matter in different states are subject that are taught in the 6th grade. They learn about concepts like elements and compounds in the 7th grade. I think they should be introduced it in the 8th grade before they go to high school and learn about the issues about this state.' T25 explained their view that it should be taught in the 4th grade as 'the concept of plasma, which is a state of matter, should be included in curricula where other states of matter (solid-liquid-gas) are taught. The plasma state of matter is more abstract in comparison to the other states.' T31, who thought that plasma should be introduced in the 7th grade, expressed this view as 'students see plasma which constitutes $99 \%$ of the universe in every part of their lives. Thus, it is necessary to raise this awareness at an early age. This is because the earlier it is taught, the further their skills of inquiring upon the universe will be developed.'

\section{Findings on Outcomes}

The views of the participants on the targeted outcomes of the concept of plasma that they thought should be included in science curricula are shown in Figure 2. 


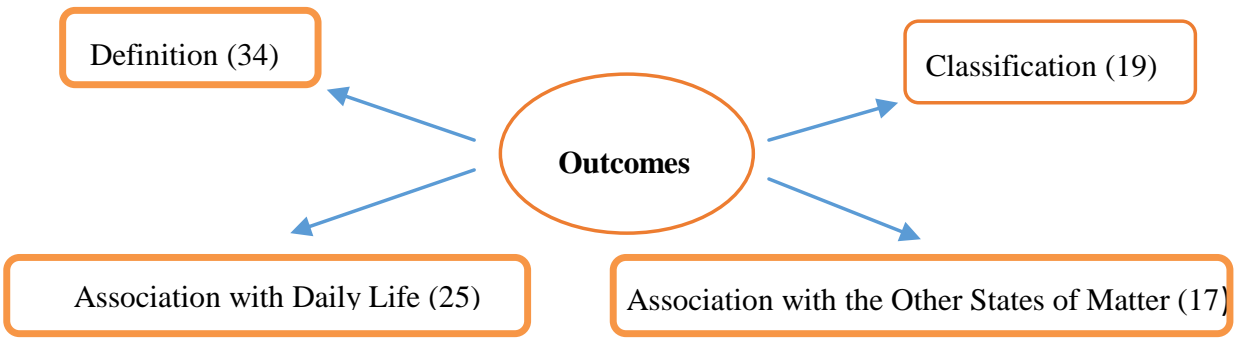

Figure 2

Vie Views of the prospective teachers on the targeted outcomes of the concept of plasma that they thought should be included in science curricula

As seen in Figure 2, the participants categorized the targeted outcomes of the concept of plasma that they thought should be included in science curricula in 4 dimensions. These were definition, classification, association with daily life and association with the other states of matter. T3 thought that the targeted outcomes in teaching plasma should be 'defines plasma, states the characteristics of plasma, states the difference between plasma and gasses, comments on the history of plasma, classifies natural and artificial plasmas.' T7 thought these should be 'defines plasma which is a state of matter, states the particles found in plasma, provides examples of plasma from daily life, compares plasma to the other states of matter.' T28 listed these outcomes as 'explains that it is a state of matter other than the solid-liquid-gas states, knows that $99 \%$ of the universe is in a plasma state, predicts that many forms of matter that cannot be defined as solid-liquidgas might be plasma.' The views of the participants on the targeted outcomes of teaching plasma suggest that, in general, they thought outcomes related to definition, classification, association with daily life and association with the other states of matter should be included.

Considering the views of the teachers on class levels, in general, they though the concept of plasma should be introduced to some extent in 4th-6th grade curricula, and it should be included in 7th and 8th grade curricula in more detail.

\section{Findings on Content}

The views of the participants on the content are given in Figure 3.

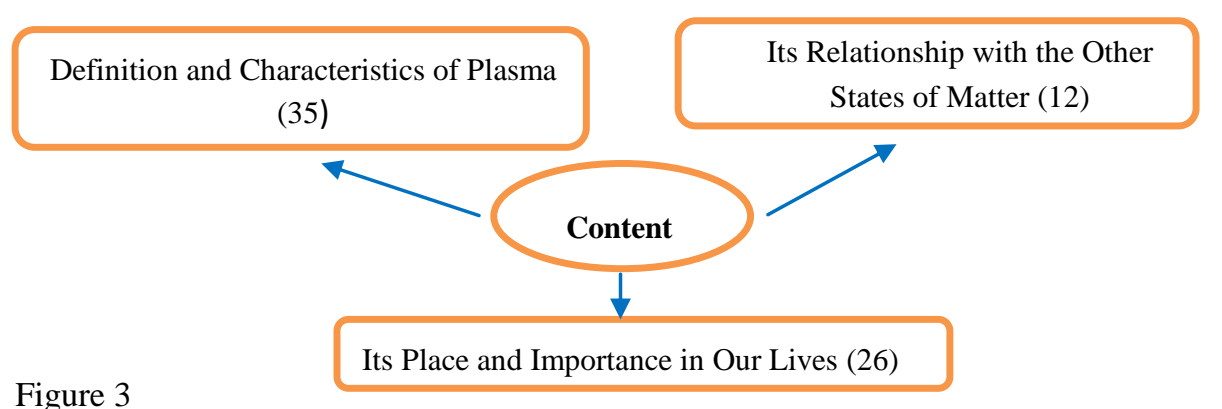

Views of the prospective teachers on the content of the concept of plasma that they thought should be taught in science curricula 
As seen in Figure 3, the participants categorized the content of the concept of plasma that they thought should be included in science curricula in 3 dimensions. These were the definition and characteristics of plasma, its relationship with the other states of matter and its place and importance in our lives. T1 thought that the content to be provided while teaching plasma should include 'the definition of plasma, examples of plasma in the world and the universe, differences between gases and plasma, particles constituting plasma and usage areas of plasma.' T8 stated that the content should include 'a general outlook of the states of matter, plasma as the fourth state of matter, natural and artificial plasmas.' T17 thought that 'initial subject titles should be attentiongrabbing things such as: Are there only three states of matter? Is it a gas or something else? A transition may be made into plasma from here. As plasma is a difficult but fun subject, we should make the titles interesting and entertaining, too. The concept of plasma may be explained shortly in the 5 th grade, and examples may be provided. More details may be provided in further grades.' T19 said, 'the content should include: What is plasma? What are its place and importance in our lives? What are its usage areas? What are the natural sources of plasma around us? What is the position of plasma in today's technology?' T33 thought the content should include 'the fourth state of matter: plasma, let us know about plasma, types of plasma, natural plasma, artificial plasma, and usage areas of plasma.' T35 said the content should include 'how many states of matter are there? What is plasma? Natural and artificial plasmas, plasma in our lives.'

\section{Findings on the Teaching-Learning Process}

The views of the participants on the teaching-learning process are given in Figure 4.

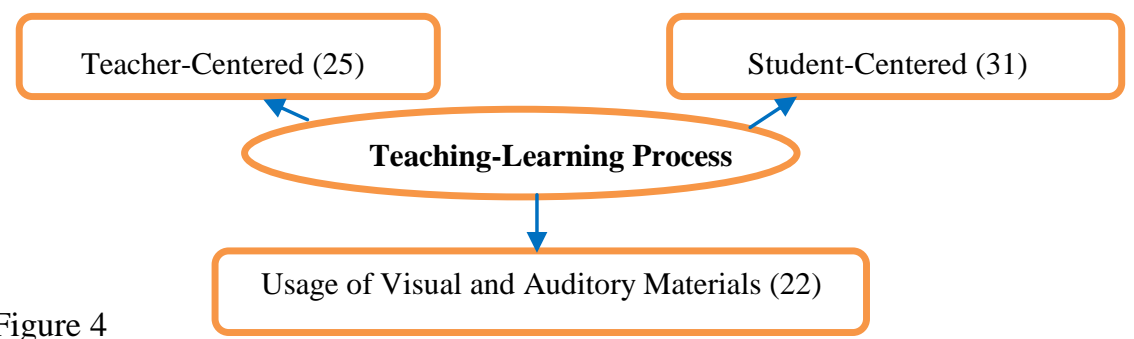

Views of the prospective teachers on the teaching-learning process of the concept of plasma to be included in science curricula

As seen in Figure 4, the participants categorized the teaching-learning process of the concept of plasma that they thought should be included in science curricula in 3 dimensions. These were teacher-centered applications, student-centered applications, and usage of visual and auditory materials. While teacher-centered applications included ordinary lecturing and questions-answers, student-centered teaching methods and techniques included techniques such as group work, concept maps, drama, brainstorming, projects, the snowball technique, and discussions. T1 said, "while starting the class, to get their attention, the teacher enters the classroom with a material based on celestial bodies and stars in the universe. They apply the question-answer technique and test the students' readiness and preliminary knowledge. Videos related to the subject of plasma are displayed by using the computer-assisted teaching technique. As it is dangerous for students, the demonstration experiment technique 
is used.' T4 stated that methods of presentation and discovery, and the theory of multiple intelligences may be used as teaching methods in the teaching-learning process. T14 stated that the teaching-learning process should be different for different class levels, photographs may be very effective for the 6th grades and therefore posters may be prepared; experiments may be included in the 7th grade, while the 8th grade may include going into the details of interesting subjects that are photographable and such as the Aurora Polaris, fluorescent and neon lamps, lightning, thunder and candle flames, as well as asking students to prepare presentations or posters under supervision of the teacher. T15 said, 'Students are not provided with more information on this topic. While teaching it, I would use visuals and materials, rather than ordinary presentation. I would firstly ask students to do some research on the subject and come back later. In the next class hour, I would start with posters I have prepared and a slideshow with a visual focus. I would continue the process with the help of questions-answers and little clues on the posters.' T17 said, 'This is the most difficult process because the subject is very heavy. We can demonstrate it using tangible, daily-life examples instead of abstract concepts. We can point to the sun when we are in class and ask about its state. This way, we can use a material to get attention. We can then teach the subject based on their levels. We can make an experiment for the children after teaching the subject and try to make it more lasting. Later, we can keep the subject fresh in their minds by questions-answers in every class. We can assign homework for them to prepare materials at home and have them draw examples of plasma in the nature.' T23 stated that the teachinglearning process may be carried out by means of story-telling and discovery: 'On the board, the teacher hangs pictures that might be examples of the solid, liquid, gas and plasma states of matter. They ask their students to categorize these in order. While they are categorizing, the teacher asks based on which characteristic of the thing in the picture they are making this categorization, and why they did so. The pictures would include examples of plasma such as the sun, stars, lightning, thunder, candle flames, neon lamps. Students might not be able to categorize these based on their preliminary knowledge. The students are asked why these pictures may be different from others and they are told to discuss in groups. The responses of the groups are written on the board.' T35 said, 'A plasma experiment is performed in the laboratory for students to see the state of plasma with their own eyes, believe it and identify it. It is ensured that students observe the experiment in a safe way.'

\section{Findings on the Measurement-Assessment Process}

The views of the participants on the measurement-assessment process are given in Figure 5.

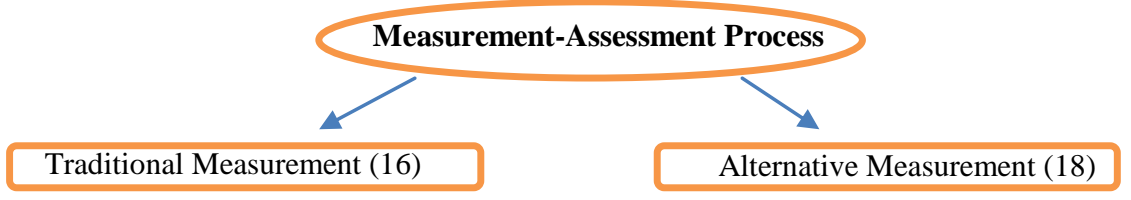

Figure 5

Views of the prospective science teachers on the measurement-assessment process to be employed in teaching the concept of plasma in science curricula

As seen in Figure 5, the participants categorized the measurement-assessment process of teaching the concept of plasma that they thought should be included in science curricula in 2 dimensions. These were traditional measurement-assessment and alternative 
measurement-assessment. While the participants categorized the traditional measurement-assessment process as questions-answers, open-ended, multiple-choice, short-answer questions, filling in the blanks and true-false tests, they considered the alternative measurement-assessment process to include discussion-debate, games, performance assignments, mind maps, project and research assignments, brainstorming, the snowball method, diagnostic tree and word association tests. T1 stated that 'Information on what is learnt is gathered by applying a questionnaire. Students' interests and attitudes towards the subject of plasma are assessed by a grading key. Their levels of knowledge are measured using the technique of discussion or debate. Misinformation is met with clues and feedback.' T7 said, 'I would make an assessment using multiple-choice questions, concept and mind maps at the end of teaching the subject and use open-ended questions in the process. At the end of the process, I would carry out a success-improving assessment process with measurement tool that would increase the creative thinking skills of students by considering individual differences.' T19 explained their opinion as 'Measurement-assessment could be performed by assigning research on places where plasmas are used in today's technology, giving research project homework and supporting these by presentation.' T21 responded as 'For measurement-assessment, performance assignments may be provided for getting more output from students. Examination questions should be open-ended, fill-in-theblanks, multiple-choice and true-false questions.' T35 said, 'At the end of the class, students are given paper balls including intertwined questions previously prepared by the teacher (the snowball technique). Students throw this ball at each other, and the one who catches the ball answers a question. This way, the teacher understands whether students comprehended the subject or not.'

\section{DISCUSSION AND CONCLUSION}

The main philosophy of the education system in Turkey is based on making knowledge meaningful and experiential for the individual, instead of assessing the individual's level of knowledge (Turkish Ministry of National Education (MEB), 2017). From here, it is highly important that the concept of plasma and education on plasma are introduced to students on the levels of primary school and middle school, it is achieved that this concept is established in the minds of students, and students are able to correctly identify the contents around them related to the concept of plasma. This is why the purpose of this study was to investigate where and how the concept of plasma should be included in science curricula. It is believed that students perceive the concept of plasma as abstract as they cannot visualize it in their minds. It was seen that, even though their numbers were low, some prospective teachers included in the study still perceived this concept as an abstract one despite having received training on the subject. The reason for this might be not the inadequacy of the education they received about the concept of plasma, but that they were not completely sure of what is abstract and what is not, or that they could not form the concept in their minds or that they formed it too late. Even this result reveals the necessity of providing students with tangible examples in teaching this concept at early ages in order to establish development of the concept of plasma in their minds. 
According to the results of the study, it was seen that the prospective science teachers provided views on inclusion of the concept of plasma in science curricula on different class levels (4-5-6-7-8th grades). The mostly stated that it should be included in the 6th, 7 th and 8th grades. It was seen that, in general, the participants thought it would be suitable to introduce the concept in lower levels such as the 4th to 6th grades and more detail should be provided in further levels such as the 7th and 8th grades. Bülbül (2009) reported that the concept of plasma may be introduced on the level of primary education by considering the cognitive levels of students and provided examples of how it might be taught on this level. This result agrees with the results of this study.

The participants categorized the targeted outcomes that they thought should be included in science curricula while teaching the concept of plasma in four dimensions. These were, definition, classification, association with daily life and association with the other states of matter. Nevertheless, considering that the targeted outcomes of MEB in the science curriculum of 2017 that include "classifies matter around based on its state, provides examples from daily life but does not mention their structure (viscosity, distance between particles, etc.)" only refer to the states of solid-liquid-gas and their daily life examples, this study shows that the concept of plasma and its daily life examples may be introduced for the students. Examples may include the sun, the stars, lightning, thunder and flames, which students always see. It may also be seen that there are targeted outcomes as "compares the basic characteristics about the states of matter. Particular and cavernous structure is not introduced. Provides examples of different states of the same matter" in the field of Characteristics of Matter / Matter and Its Nature in the fourth unit of the fourth-grade curriculum, and these outcomes included the solid, liquid and gas states of matter only. Here, what is meant by a basic characteristic is whether or not the substance has a certain shape and volume. At this point, it may be stated that plasmas do not have a certain shape or volume. Again, it is seen that there is the targeted outcome of "explains the characteristics of the sun" within the subject of the Sun, the Earth and the Moon / the Earth and the Universe included in the first unit of the fifth grade. Accordingly, considering that the sun is a plasma and it is related to astronomy, learning this subject field is dependent on the contribution of the concept of plasma. Again, it may be seen that there is an outcome of "makes inferences on the possibility that matter may change states due to heat based on the data they obtain through experiments" in the subject field of Matter and Change / Matter and Its Nature. Here, children may be shown the flame of a stove and told that this flame is a more energetic form of gas, that is, plasma. Actually, replacing the term "due to heat" with "due to energy" here may facilitate better expression of the term plasma. Meanwhile, the fourth state of matter, plasma, may be demonstrated by an experiment using a Geissler Tube, which is included in experiments sets especially in middle school. It is seen that the subject field of Matter and Heat / Matter and Its Nature in the fourth unit of the sixth-grade curriculum has the targeted outcomes of 'states that matter has a particular, cavernous and dynamic structure, mentions the concepts of vibration, shifting and rotation in relation to the dynamic structure, makes comparisons on how the distance among particles and the motility of particles change based on the change in the state of matter' and it is shown that the particular, cavernous and mobile structural 
characteristics are given in the sense of the states of the matter as solid, liquid and gas. Here, it may be stated that the fourth state of matter is a state of gas that has more energy, the interaction among its particles is high, and therefore, the particles will have a collective response to the influences coming from outside. It may be stated that plasmas have a fluid and cavernous structure, and they perform movements of rotation, shifting and vibration. Considering that the star that is referred to in the targeted outcome of the subject field of the Solar System and Beyond / the Earth and the Universe in the first unit of the second grade as 'notices the star formation process. Mentions the concept of being nebular, explains the concept of stars and talks about types of stars' is a plasma and it is related to astronomy, it is needed to teach the concept of plasma in order for this field to be taught better. Additionally, it is seen that the concept of ionization is taught to students in the seventh grade. The fact that a simple definition of plasma is "the ionized state of gas" will make it easier to identify the concept of plasma.

The participants categorized the content of the concept of plasma that they though should be included in science curricula in three dimensions. These were the definition and characteristics of plasma, its relationship with the other states of matter, and its place and importance in our lives. If the science course is considered in terms of its content for MEB (2017) it is seen that the course is provided as a requirement of the spiral program from the third grade to the eighth grade. In this program, the subjects of the solid-liquid-gas states of matter are also presented in an equivalent format in terms of the concept of plasma's definition and characteristics, and its relationships with the other states of matter, as well as its place and importance in our lives. This is why the concept of plasma may be included in primary school and middle school science curricula with its definition and characteristic, its relationship with the other states of matter, and it place and importance in our lives. Another factor that needs to be accounted for here is that the word plasma has an unfamiliar tone in children. Children may experience issues when they hear this unfamiliar word for the first time. This is why it is important to express the concept of plasma by simplification for students' familiarization with the concept. For example, this may be explained as 'the universe consisted from the beginning of four elements of nature. These were earth, water, air and fire. Earth is the universe's solid state, water is its liquid state, air is its gas state and fire is its plasma state.' Additionally, students may be told that the word plasma is a new word that has been used in the last fifty-sixty years and it may be ensured for them to understand the subject better.

The participants categorized the teaching-learning process of the concept of plasma that they thought should be included in science curricula in three dimensions. These were teacher-centered applications, student-centered applications and usage of visual and auditory materials. While the mentioned teacher-centered applications included ordinary lecturing and questions-answers, the student-centered techniques included methods such as experimentation, group work, concept maps, drama, brainstorming, projects, the snowball technique and discussions. According to MEB (2017), a comprehensive approach was adapted in the science curricula in terms of teaching-learning theories and practices, and in general, it was accepted that the student is responsible for learning, their active participation in the learning process is assured, and a learning strategy of 
transferring knowledge is adopted. It is recommended that, as much as possible, performances expected from students such as project development, model and product creation, product introduction, etc. are carried out in the classroom and under supervision of the teacher. It is expected that activities are carried out in the school environment with their peers.

The participants categorized the process of measurement-assessment of teaching the concept of plasma that to be included in science curricula in two dimensions. These were traditional measurement-assessment and alternative measurement-assessment. While the participants categorized traditional measurement-assessment processes as question-answer, open-ended, multiple-choice, short-answer questions, they stated alternative measurement-assessment to include discussion-debate, gameplay, performance assignments, mind maps, project and research assignments, brainstorming, the snowball technique, diagnostic tree and word association tests. According to MEB (2017), the measurement and assessment approach in science curricula not only teaches the targeted outcomes but it also facilitates reaching these for students by their own means. This will not only improve the self-esteem and self-regulation of students, but it will clear their way for learning. Furthermore, the student should focus on, firstly, verbally, and then, in a written way, to assess themselves regarding their learning process, performance, and production. As in all other studies, individual factors should be considered with great care and attention in measurement and assessment processes. In this sense, the results of the study agree with the principles set forth by MEB in 2017.

As there were not many studies in the literature related to the purpose of this study, the findings were mostly interpreted and discussed in the context of science curricula. For this reason, researchers need to work on teaching the concept of plasma. Researchers should also consider cognitive development of children when performing these studies. Thus, program specialists can also study the results of these surveys and conduct infrastructure studies to include the concept of plasma in primary and secondary school programs.

\section{SUGGESTIONS}

- The concept of plasma, the fourth state of matter, may be taught on levels of primary school and secondary school in connection to the cognitive development levels of students.

- How the concept of plasma will be taught in primary education and secondary school and how it will be included in curricula may be planned in cooperation with curriculum experts. In addition activities may be arranged for teaching the concept of plasma on these levels..

\section{REFERENCES}

Ausubel, D. P. (1963). The Psychology of Meaningful Verbal Learning. Grune \& Stratton: Newyork.

Başar, V. (1992). Ortaokullar İçin Uygulamalı (Projeli) Fizik (Fen) Öğretimi-ÖdevleriSergi ve Yarışmaları. MEB Yayınları, İstanbul. 
Bilgin, A,. \& Balbağ, M.Z. (2016). Personal professional development efforts scale for science and technology teachers regarding their fields, Acta Didactica Napocensia, 9(2), 67-78.

Bülbül, F. (2009). Plazma Kavramına Dair. Kastamonu Eğitim Dergisi, 17(1), 279-288.

Creswell, J. W. (1998). Qualitative inquiry and research design: Choosing among five traditions. Thousand Oaks, CA:Sage.

Çiçek, Ş. (2008). Lise II Öğrencilerinin kimya dersinde başarıları ve tutumları üzerine bilim şenliklerinin etkisinin incelenmesi. Yüksek lisans tezi, Gazi Üniversitesi, Fen Bilimleri Enstitüsü, Ankara.

Grill, A. (1993). Cold plasma in materials fabrication, IEEE pres, New York, p.256.

Hewson, M. G., \& Hewson, P. W. (1983). Effect of instruction using students' prior knowledge and conceptual change strategies on science learning. Journal of Research in Science Teaching, 20(8), 731-743.

Kranz, W. (1994). Antik Felsefe: Metinler ve Açıklamalar, Sosyal Yayınları, Kısım I, Çev. Suad Y. Baydur, İstanbul.

MEB. (2017). İlköğretim Kurumları (Illkokullar ve Ortaokullar) Fen Bilimleri Dersi (3, 4, 5, 6, 7 ve 8. Sinıflar) Öğretim Programı, Ankara: Milli Eğitim Bakanlığı Yayınevi.

Nakhleh, M. B. (1992). Why some students don't learn chemistry. Journal of Chemical Education, 69(3), 191-196.

Pardo, J. Q., \& Partoles, J. J. S. (1995). Students and teachers misapplication of Le Chatelier's principle: implications for the teaching of chemical equilibrium. Journal of Research in Science Teaching, 328(9), 939-957.

Rubin. D. B. (1983). William G. Coehran's contributions to the design, analysis, and evaluation of observational studies. In Research Work of William O. Cochran, Eds. S. Rao and J. Sedransk. New York: Wiley. To appear.

Tanenbaum, B. S. (1967). Plasma physics, McGraw-Hill book company, New York, p. 360.

Tonks, L., \& Langmuir, I. (1929). Oscillations in ionized gases, Physics Review, 33, 195.

Topdemir, H. G., \& Unat, Y. (2009). Bilim Tarihi, Pegem Akademi, 2. Bask1.

Varış, F. (1996). Eğitimde Program Geliştirme "Teori ve Teknikler". Ankara: Alkım

Kitapçı1lı Yayıncılık.

Yıldırım, A., \& Şimşek, H. (2008). Sosyal Bilimlerde Nitel Araştırma Yöntemleri, Seçkin Yayınevi, Ankara.

Zoller, U. (1990). Students' misunderstandings and misconceptions in college freshman chemistry (General and Organic). Journal of Research in Science Teaching, 27(10), 1053-1065. 